\title{
FIEBRE AMARILLA Y LA NECESIDAD CONSTANTE DE VIGILANCIA EPIDEMIOLÓGICA
}

\section{ARTÍCULO ORIGINAL}

GITIRANA, José Valdeci Almeida ${ }^{1}$

GITIRANA, José Valdeci Almeida. Fiebre Amarilla y la necesidad constante de vigilancia epidemiológica. Revista Científica Multidisciplinar Núcleo do Conhecimento. año 04, Ed. 11, Vol. 06, págs. 05-15. Noviembre de 2019. ISSN: 24480959, Enlace de acceso: https://www.nucleodoconhecimento.com.br/salud/fiebreamarilla

\section{RESUMEN}

Objetivo: revelar los factores que justifican la importancia de una vigilancia epidemiológica eficiente para el control de la fiebre amarilla en el país. Método: investigación exploratoria, bibliográfica, cualitativa y descriptiva. Resultados: las últimas encuestas epidemiológicas indican que el número de casos de fiebre amarilla silvestre registrados en Brasil es muy variable, por lo tanto, si se considera que para cada caso detectable hay otros 10 casos de evolución subclínica, las cifras reales pueden ser mucho más grandes que los registrados por las agencias de salud. Conclusión: La fiebre amarilla, como enfermedad infecciosa aguda, es una zoonosis difícil de controlar, ya que es capaz de causar epidemias impredecibles en las poblaciones humanas, un ejemplo es el momento experimentado por el Estado de Minas Gerais, que sufre de un brote de enfermedad, motivada por condiciones de desequilibrio ambiental que favorecen el desarrollo y proliferación de vectores, cooperando para la aparición de cientos de muertes solo en los primeros meses de 2017.

\footnotetext{
${ }^{1}$ Especialista en Análisis Clínico, Graduado en Farmacia, Actualmente académico médico.
} 
Palabras clave: control, fiebre amarilla, diagnóstico, vigilancia epidemiológica.

\section{INTRODUCCIÓN}

La fiebre amarilla es una enfermedad infecciosa aguda, que es un grave problema de salud pública en la mayoría de los países tropicales, donde las condiciones ambientales favorecen el desarrollo y la proliferación de vectores, causando decenas de casos de muertes Anualmente. Puede presentarse en formas leves o subclínicas e incluso formas graves caracterizadas por la tríada que consiste en ictericia, hemorragias e insuficiencia renal aguda, con una tasa de mortalidad, en casos graves, entre el 20 y el $50 \% .{ }^{24}$

El agente etiológico de esta enfermedad es un arbovirus del ARN perteneciente a la Familia Flaviviridae. Este virus permanece en la naturaleza en un ciclo salvaje, teniendo primates como reservorio y mosquitos del género Hemagogos como vectores, y otro urbano, en el que el embalse es el propio hombre y tiene el mosquito Aedes aegypti como vector, en este caso específico la enfermedad es transmitido de hombre enfermo a hombre uninmunizaizado a través de la picadura vectorial. ${ }^{25}$

Clínicamente, el período de incubación suele ser de tres a seis días. Sin embargo, ya se han descrito períodos más largos. El espectro clínico de la enfermedad va desde una afección benigna, caracterizada por una enfermedad febril inespecífica, hasta una enfermedad fulminante caracterizada por disfunción multiorgánica, en particular hemorragias1. Por lo tanto, el paciente puede pasar un período asintomático, con fiebre posterior, dolor de cabeza, dolor muscular generalizado, fotofobia, escalofríos, ictericia, y puede evolucionar con condiciones de sangrado e insuficiencia renal aguda 2,3.

La fiebre amarilla es una enfermedad de notificación obligatoria y todos los casos sospechosos deben confirmarse en laboratorio. El diagnóstico debe justificarse a través de datos epidemiológicos, manifestaciones clínicas descritas para las diversas formas y datos de laboratorio. Sin embargo, se obtiene un diagnóstico más preciso mediante la investigación serológica de anticuerpos específicos y el análisis 
histopatológico e inmunohistoquímico de muestras hepáticas 4. Desde el punto de vista patogenético, se pueden observar lesiones en el hígado, los riñones, el corazón, el bazo y los ganglios linfáticos 1 , sin embargo, la lesión más importante de esta enfermedad ocurre en el hígado a nivel de hepatocitos.

El virus causante de la fiebre amarilla está clasificado taxonómicamente de la familia Flaviviridae, género Flavivirus. Flavivirus es esférico, envuelve y mide unos 40-50 nm. Su genoma (ARN) consiste en una cinta única, lineal y no segmentada, que presenta un coeficiente de sedimentación de 44S, que contiene aproximadamente 10.0862 nucleótidos, peso molecular de $4 \times 106 \mathrm{kd}$, tienen 10 genes, que codificarán 10 proteínas: tres proteínas C, M, E; y siete proteínas no estructurales, NS1, NS2a, NS2b, NS3, NS4a, NS4b y NS5 ${ }^{5}$.

La proteína C puede estar en cápside viral. Las proteínas M y E son componentes de la envoltura viral. La proteína $E$ es glucosilada y tiene determinantes antigénicos importantes, principal responsable de inducir la respuesta inmune y también tiene un valor considerable para la unión del virus con el receptor de la membrana huésped. La proteína M (no glicosilada) es el resultado del escote de la proteína pre-M (glucosilada) 1.

Sin embargo, hay estudios que también han enfatizado la importancia de las proteínas NS1 y NS3 en la respuesta inmune del huésped. El primero tiene la capacidad de activar el complemento e inducir la lisis de las células infectadas, mientras que NS3 es uno de los principales objetivos del ataque de linfocitos T citotóxicos 6 .

Después de la penetración de partículas virales en el citoplasma y el denudemento, el ARN se replica en regiones perinucleares, mediada por un ARN de polaridad negativa. La maduración de los visrions se produce en membranas intracelulares, con el virus brotando del aparato Golgi o del retículo endoplasmático, y se pueden definir dos tipos distintos de partículas virales: los virus asociados con las células y partículas virales extracelulares. ${ }^{26}$ 
Los virus pertenecientes a la familia Flavivindae tienen la capacidad de replicarse tanto en mosquitos como en primates, incluido el hombre. Tienen una gran adaptabilidad, lo que implica decir que esta característica tiene una relación directa en el mantenimiento de estos virus en la naturaleza. ${ }^{27}$

A partir de un criterio eminentemente epidemiológico, se puede definir el virus de la fiebre amarilla como un arbovirus cuyo ciclo primario involucra principalmente mosquitos forestales $\mathrm{y}$ especies de primates no humanos, especialmente Callitrichidae y Cebidae, entre los primates neotropicales, la mayoría de las especies en América del Sur cuando se infectan, en general, la evolución fatal actual, un hecho no observado en especies africanas. Del mismo modo, especies como aves, roedores, marsupiales, carnívoros, anfibios y reptiles son generalmente resistentes al virus de la fiebre amarilla 7.

Los mosquitos involucrados como vectores de la fiebre amarilla son antropofílicos de la actividad diurna en las copas de los árboles, en el entorno salvaje y por lo tanto la infección humana es accidental y consecuente a la penetración humana en el lugar donde se produce la zoonosis. En el entorno urbano es necesaria la presencia de vectores que viven en el hogar o peridomicilio del hombre urbano 1.

Varias especies vectoriales de esta patología han sido estudiadas a lo largo de los años y pueden variar según la región investigada, entre ellas podemos mencionar: Haemagogos janthimomys, Haemagogus albomaculatus y leucocelaenus, $\mathrm{Hg}$. janthinomys, Sabethes chloropterus y Sabethes soperi, Aedes abopictus y Aedes aegypti, entre otros. ${ }^{28}$

Desde el punto de vista de la transmisión, el hombre desempeña un papel importante en la propagación del virus a zonas donde no se produce de forma natural, pero que tienen vectores y monos, que forman parte del ciclo de transmisión de la enfermedad. Además, los cambios en el bosque, generalmente causados por la apertura de carreteras, la tala y la actividad agrícola, exponen accidentalmente a los individuos no inmunizados a vectores invertebrados salvajes, siendo una de las principales formas de transmisión de enfermedad en la Amazonía brasileña ${ }^{3,4}$. 
Vale la pena recordar que, aunque no sea frecuente en nuestro país, otra forma de mantenimiento del virus en la naturaleza puede ocurrir en las zonas urbanas, con Aedes aegypti siendo el vector involucrado y el hombre el único huésped. La forma urbana de la fiebre amarilla fue erradicada de Brasil en 1942. Sin embargo, los estudios han demostrado la presencia de Aedes aegypti en unos 21 estados brasileños 7.

Por lo tanto, un paciente viremico de una zona endémica de fiebre amarilla salvaje puede constituir, asociado con las altas densidades de Aedes aegypti, un estímulo potencial para la reurbanización de la fiebre amarilla, que tendría graves consecuencias especialmente para la población inmunizada anteriormente ${ }^{7.4}$.

Los estudios han planteado la hipótesis de una posible participación de Aedes albopictus en el ciclo de transmisión de la enfermedad, cuya capacidad para transmitir el virus ya se ha demostrado en el laboratorio1,8,9. Debido a que este agente puede reproducirse en entornos rurales, periurbanos y urbanos, potencialmente puede servir como puente entre el ciclo salvaje y urbano de la fiebre amarilla. En Africa, varias especies del género Aedes, como Aedes furcifer, Aedes taylori y Aedes luteocephalus, son vectores urbanos tan importantes como Aedes aegypti ${ }^{5}$.

La respuesta a la infección por amarílica es amplia y variable, en esta perspectiva, se estima que alrededor del $90 \%$ de los casos con expresión clínica son de las formas clasificadas como leves y oligosintomáticas, es decir, presentando pocos síntomas y que sólo el $10 \%$ son de las formas Serio. Además, hay personas que desarrollan afecciones asintomáticas ${ }^{8}$.

Estas formas asintomáticas, así como los casos subclínicos y las formas leves de la enfermedad a menudo se notan en niños de baja edad cuyas madres fueron vacunadas y les transmitieron anticuerpos maternos $\lg G{ }^{9}$. Por otro lado, hay individuos que desarrollan formas más graves de la enfermedad, como personas que nunca han sido vacunadas y, por lo tanto, están completamente indefensas a la enfermedad. Estos individuos, a su vez, desarrollan condiciones clínicas graves y extremadamente graves de la enfermedad. 
Cabe destacar que en las formas leves y moderadas de la sintomatología de la enfermedad es indiferenciada y no es característica, es decir, se confunde con muchas enfermedades comunes en zonas endémicas, como el paludismo, la hepatitis viral, la fiebre tifoidea, entre otras ${ }^{1} 0$.

En general, los síntomas en forma leve se limitan al dolor de cabeza y a la asistencia, acompañados de febrilcula o fiebre moderada. Evoluciona hasta dos días, después del final de estos el paciente se recompone sin mostrar secuelas. En su forma moderada, el paciente además de poder presentar estos síntomas puede incluso ir acompañado de náuseas con ausencia de vómitos, además de mialgias y artralgias que ni siquiera molestan al paciente o impiden su locomoción.

El dolor de cabeza generalmente dura más tiempo. La fiebre sólo termina con el uso de arena antitérmica que ya son más persistentes. Al menos una de las indicaciones clásicas de la enfermedad se acompaña de este cuadro sintomático: ictericia u oliguria/anuria y hematonesis (vómitos negros)8. La duración de dicho estado es de dos a tres días y la recuperación es integral. La imagen evoluciona en dos períodos, con una fase de remisión entre ellos. Sin embargo, hay que subrayar que no siempre es posible separar esas fases. ${ }^{8}$

La sintomatología de la forma clásica de la fiebre amarilla es grave y se caracteriza por un inicio abrupto, después de un período de incubación promedio de 6 días (período que va desde la infección de la picadura hasta la aparición de la manifestación de los síntomas) y que puede durar alrededor de dos semanas. Al principio hay fiebre alta, en la que el paciente informa haberse sentido bien y completado sus ocupaciones unas horas antes de las 8 . La fiebre no está acompañada por el aumento del pulso ${ }^{1} 1$.

Por el contrario, es común observar fiebre alta con caída de pulsación, tal signo se conoce como signo de faget ${ }^{12}$. Poco después de la aparición de la fiebre, el dolor de cabeza holocraneal de tal intensidad se manifiesta que el paciente a menudo siente la necesidad de solicitar el uso de analgésicos ${ }^{1} 3$. 
Estas situaciones acompañan el dolor muscular difuso, especialmente en la espalda, donde suelen estar presentes. La astesia, la postración y las náuseas concluyen este cuadro que evoluciona de 2 a 3 días y coincide con el período prodrómico 8 .

En varios pacientes, evolucionando al período infeccioso, hay una fase de mejoría que se caracteriza por una sensación de alivio y cura inmediata por parte del paciente, porque la fiebre baja o de lo contrario cesa, el dolor muscular disminuye y el dolor de cabeza pasa a un estado Soportable.

Este período dura de 12 a 48 horas y, después de eso, a diferencia de los individuos que desarrollan las formas leves y moderadas que realmente curan, el estado de estos pacientes empeora repentinamente, con el empeoramiento de todos los síntomas presentados previamente, junto con el aparición de otras ${ }^{1} 1$. Esta señal es el comienzo del período de intoxicación, toxémica o "fase de localización", ya que en este período el virus se vuelve circular en la sangre para ser localizado sólo en el hígado. En él las náuseas se intensifican y los vómitos surgen abruptamente. Estos síntomas se están comiendo y luego ampliamente hemorrágicos ${ }^{12}$.

Los vómitos son de color manchado del café si la sangre ha sufrido reacción por jugo gástrico, o ampliamente hemorrágica si el sangrado es reciente o intenso. Se evidencia que se encuentran comúnmente otras manifestaciones hemorrágicas. Las hemorragias más presentes son de tejido tegummentario, encías y oído ${ }^{14}$. En el tracto gastrointestinal, la melena puede ocurrir, cuando la hemorragia estomacal es ancha o cuando presenta la manifestación del sangrado intestinal ${ }^{1} 5$.

Acompañando o incluso sangrando anteriormente, existe la presencia de trombopenia, a menudo tan intensa que puede alcanzar menos de $20.000 / \mathrm{mm} 3$ de sangre. Es interesante mostrar que algunos pacientes, incluso con tales niveles de plaquetas, no sangran. Mientras que otros con tasas entre 50.000 y 100.000 plaquetas manifiestan sangrado exorbitante. Se observa que el grado de intensidad de la hemorragia no siempre está interconectado con el recuento de plaquetas ${ }^{1} 4$. 
Entre estos síntomas, aparece la ictericia, la existencia de color amarillento en la piel y los ojos escleróticos ${ }^{1} 4$. La ictericia es, en resumen, del tipo verdainiano y se debe al hecho del aumento de la fracción directa 8. Alrededor del 50 al 70 día del período estatal, se instala insuficiencia renal, que inicialmente se presenta debido a la disminución del volumen urinario y, si no se trata rápidamente, puede desencadenar anuria y detener completa la diuresis debido a la necrosis tubular aguda generalizadas que se instalan. Este es el momento en que las muertes 11,12 ocurren con mayor frecuencia.

Los que sobreviven se recuperan lentamente, pero totalmente y sin sequelas. Durante la convalecencia, la indisposición, la asteria y el dolor muscular se extienden hasta dos semanas.

Vale la pena señalar que en Africa a menudo se notifica la ocurrencia de formas fulminantes, que se caracterizan por una evolución de hasta tres días, resultante de insuficiencia renal y, casi siempre, sin la presencia de ictericia o incluso alteraciones hepáticas ${ }^{1} 6$.

En otros casos extremos y raros de muerte tardía debido a la fiebre amarilla pueden destacarse, casos que están asociados con lesiones cardíacas tardías ${ }^{17}$. Por último, no se puede subrayar que en los casos en que la ictericia es abrupta y los niveles séricos de bilirrubina son muy altos, es frecuente la encefalopatía, siendo un signo de mal pronóstico. Sin embargo, la mayoría de los pacientes progresan hasta la muerte ya sea por insuficiencia hepatorenal o debido a sangrado, que a menudo es incontrolable.

El examen específico para el diagnóstico definitivo de la fiebre amarilla es el aislamiento del virus, también llamado examen de cultivo. A través de este examen es posible detectar antígenos virales y ARN viral ${ }^{9}$. Además, es posible diagnosticar la enfermedad mediante el uso de métodos serológicos, como la dosificación de anticuerpos específicos por el método ELISA MAC mediante la captura de IgM en un ensayo enzimático o conversión serológica en pruebas de inhibición de la hemaglutinación $(\mathrm{IH})^{18}$. 
En esta perspectiva, el aislamiento del virus se puede hacer mediante la combinación de diferentes sistemas, como en el caso de aislamiento del virus, esto sólo será posible después de la inoculación de la muestra sospechosa, cuando la evidencia de replicación viral se obtiene alrededor del 50 al 7o Día de la cultura. Así, cuando se separan, la muestra viral puede identificarse en pruebas de inmunofluorescencia indirecta, utilizando anticuerpos monoclonales o alternativamente mediante pruebas de fijación de complemento ${ }^{1} 6$.

Por otro lado, los métodos serológicos que indican lgM específico, como en el caso de Mac ELISA, pueden dar un diagnóstico presuntivo ágil con una muestra serológica, si se recoge del paciente a partir del 50 día de la enfermedad ${ }^{19}$. Por lo tanto, la manifestación de lgM puede ser el resultado de una infección reciente (2-3 meses) o actual (actual), por esta razón la importancia de tener la historia epidemiológica y clínica completa para la interpretación del resultado del laboratorio. Es importante destacar que la vacunación antiamarílica puede fomentar la formación de $\operatorname{lgM}$ y, por lo tanto, es extremadamente importante conocer el historial de vacunación del paciente.

Como todavía no hay un medicamento específico y eficaz para el tratamiento de esta enfermedad, las pruebas que diagnostican como positivas para la infección toman alrededor de una semana. El tratamiento de apoyo debe iniciarse inmediatamente, y la hospitalización del paciente con formas graves en hospitales con una buena preparación de infraestructura para cualquier enfermedad y preferiblemente en la $\mathrm{UCI}$ es enfática, ya que es necesario procedimientos que sólo están deliberando más fácilmente en estas unidades ${ }^{1} 2$.

Sin embargo, el tratamiento farmacológico sólo debe centrarse en combatir los síntomas, por lo que el medicamento que se prescriba depende de las manifestaciones clínicas del paciente, pero es habitual utilizar antitérmicos y analgésicos en las dosis comúnmente indicadas, que van desde según factores como la edad y el peso. 
Cabe destacar la contraindicación del uso de medicamentos que tienen ácido acetilsalicílico o sus derivados en su fórmula, ya que puede agravar los fenómenos hemorrágicos que pueden estar asociados con la evolución de la enfermedad ${ }^{8,1}$.

Con los vómitos, el control de medicamentos como la metoclopramida es frecuente. Además, se recomienda el uso de medicamentos para preservar la mucosa gástrica, llamadas bloqueadores de $\mathrm{H} 2$, como la cimetidina y la ranitidina, con estos como ejemplo, que son extremadamente útiles para prevenir el sangrado gástrico. Estos sangrados pueden consolidarse como una de las complicaciones más fatales de la fiebre amarilla. Cuando se evidencia insuficiencia renal a través de oliguria, es importante que se prescriban medicamentos diuréticos ${ }^{19}$.

No se puede enfatizar que la evaluación del paciente debe ser constante e incluye acciones tales como la investigación de signos vitales, diuresis, y la solicitud de al menos las siguientes pruebas: hemograma, plaquetas, resumen de orina y verificación de las funciones hepáticas ( dosis de aminotransferasas, bilirrubina y rango GT) y renal (dosis de urea y creatinina, y monitoreo del equilibrio hídrico)19. Por lo tanto, dadas las condiciones en las que los pacientes tienen insuficiencia renal instaladas y no responden a diuréticos comunes es importante indicar hemodiálisis o diálisis peritoneal, dependiendo de la evolución del paciente y considerando el empeoramiento de la afección.

\section{MÉTODO}

La fiebre amarilla ha sido en el pasado como un gran martirio para la población brasileña e incluso hoy, a pesar de la existencia de la valina antiamarílica, es motivo de preocupación. Sobre todo, debido a la gravedad que puede alcanzar e incluso puede evolucionar hasta la muerte. Es una enfermedad infecciosa aguda, que es un grave problema de salud pública en muchos países tropicales, donde las condiciones ambientales favorecen el desarrollo y la reproducción de vectores. Su agente etiológico es un arbovirus del ARN perteneciente a la Familia Flaviviridae. ${ }^{4}$ En este trabajo, se lanza una visión global sobre las diversas formas de hacer frente a este 
gran problema de salud pública y sobre la importancia de su control a través de un eficiente sistema de vigilancia de la fiebre amarilla.

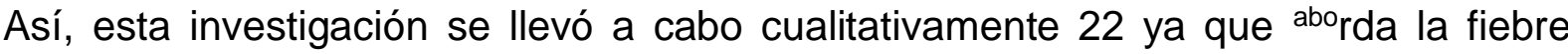
amarilla, haciendo hincapié en la necesidad de una vigilancia epidemiológica constante. En esta perspectiva, este artículo se presenta de forma descriptiva, sobre la base del aspecto teórico utilizado en la investigación, informando de las principales características de la patología, que reafirman la necesidad de vigilancia en el país a través de acciones que hacer hincapié en la prevención.

\section{RESULTADOS}

La fiebre amarilla es una enfermedad de notificación obligatoria y, como tal, cualquier caso con sospecha debe comunicarse inmediatamente a la autoridad sanitaria local, estatal o nacional, que a su vez tiene el deber de informar del caso a los organismos internacionale ${ }^{\mathrm{s} 2} 0$.

Si se confirma o se elimina, la notificación del caso se pasa a la autoridad nacional, que a su vez confirma o descarta la citación a la autoridad sanitaria internacional. Esto siempre debe hacerse para acelerar las medidas preventivas y prevenir posibles brotes ${ }^{21}$.

Es importante destacar que el método más eficiente para prevenir la aparición de fiebre amarilla sigue siendo la vacunación con la muestra 17D. Desde esta perspectiva, se advierte que todas las personas sanas de más de seis meses de edad, que están expuestas o expuestas a una posible contaminación por infección 8,10,16, están debidamente vacunadas.

Una dosis única de la vacuna protege al individuo durante al menos 10 años, durante los cuales se recomienda la revacunación. Sin embargo, vale la pena destacar que algunos estudios han demostrado que las personas vacunadas sólo una vez y que viven lejos de las zonas de riesgo indican anticuerpos neutralizantes durante un máximo de 35 años, lo que denota la fiabilidad y eficacia de la vacuna ${ }^{1} 6$. 
Teniendo en cuenta el hecho de que la vacuna se produce con el virus vivo atenuado, no es aconsejable que las personas con inmunodeficiencia a riesgo de reversión de la virulencia en un huésped con depresión del sistema inmunitario se vacunen ${ }^{2} 9$.

Los pacientes con cáncer, SIDA/SIDA y el uso de medicamentos que disminuyen la respuesta inmunitaria del cuerpo no deben ser vacunados, excepto en casos específicamente predeterminados por la autoridad médica 8.

Por lo tanto, además de la vacunación, la lucha contra los vectores y el uso de la protección individual son formas de prevención de la fiebre amarilla, pero no debe perderse teniendo en cuenta que la lucha contra los vectores forestales es básicamente inviable, de modo que la lucha contra el vector urbano se convierte en relativamente fácil ${ }^{2} 9$.

\section{DISCUSIÓN}

Teniendo en cuenta el reciente brote de fiebre amarilla salvaje que afecta a la zona rural del estado de Minas Gerais y se propaga por todo el país, es innegable destacar que es deber de la coordinación del Programa de Vigilancia y Control de la Fiebre Amarilla (PVCFA) encontrar soluciones para mejorar y sofisticadamente la vigilancia de la enfermedad en el territorio nacional, entre las acciones que abarcan este deber se encuentran: definir áreas de riesgo, permitir que los laboratorios dispongan de los medios para identificar casos de la enfermedad, promover acciones de educación sanitaria para para sensibilizar sobre la necesidad de prevención, entre otros. Sin embargo, algunas medidas 23 deben ser dotadas para hacer más eficaz la vigilancia epidemiológica en Brasil en relación con la fiebre amarilla, tales como:

- Adoptar una definición de caso más abierta que la aconsejada por la Organización Panamericana de la Salud (OPS), preferiblemente introduciendo un enfoque sindrómico, con el propósito de aumentar la receptibilidad y utilidad del sistema ${ }^{20}$;

- Mejorar la cualificación de la información para aumentar la comodidad del sistema en el análisis y detección de tendencias históricas ${ }^{2} 0$; 
- Evolucionar el sistema de vigilancia de epizootias y entomológicacomo como ejes primordiales de detección precoz de la circulación viral en Brasil, especialmente en zonas donde la población residente aún no está vacunada ${ }^{2} 0$;

- Integrar conocimientos, nuevas técnicas y tecnologías para lograr las premisas del programa, como el uso de información geográfica para detectar posibles tendencias en la distribución y dispersión viral y verificar la correlación con los datos ambientales, entomológico y demográfico, haciendo hincapié en el desarrollo de un modelo capaz de calcular las zonas de riesgo de fiebre amarilla ${ }^{2} 0$.

Vale la pena señalar que, aunque la última manifestación de la fiebre amarilla urbana se ha documentado hace más de 60 (sesenta) años en el país, la posibilidad de reaparición no puede ser ignorada. Especialmente cuando los factores potencialmente favorables se pueden identificar fácilmente ${ }^{1} 4$.

Uno de estos factores es precisamente la dispersión de Aedes aegypti en miles de municipios, que es la necesidad de nuevas posibilidades de salud pública. Especialmente orden sanitaria ${ }^{23}$.

Además, no se puede dejar de subrayar el hecho de que el mantenimiento de la proliferación de la fiebre amarilla salvaje es una intención para la salud de la población. Debido principalmente a la capacidad epidémica que puede suponer en poblaciones urbanas que tienen tasas inferiores al 50\% de la cobertura de vacunación ${ }^{22} 3$.

En resumen, la combinación de estas ideas indica que la vigilancia de la fiebre amarilla debe trabajar codo con codo con la vigilancia de los casos humanos, la vigilancia de los epizootias en primates no humanos y la vigilancia entológica, con miras a aumentar la eficacia para circulación viral ${ }^{23}$.

¿Por qué cualquier caso sospechoso de fiebre amarilla debe transmitirse inmediatamente a los órganos apropiados y, previa notificación, se debe llevar a cabo una investigación inmediata que no debe exceder el período máximo de hasta 24 horas después de la citación, la resultado debe ser divulgado dentro de 60 días. 
Desde esta perspectiva, las acciones de vigilancia epidemiológica son acciones frente a casos humanos sospechosos:

- Detectar tantos casos con sospecha como sea posible (sintomático y asintomático) y notificarles para aumentar la evaluación de la población en riesgo;

- Encontrar casos de epizootias en el territorio con el fin de identificar la zona de riesgo;

- Guiar las acciones para controlar la epidemia (vacunación y lucha contra el vector urbano);

- Resaltar los resultados.

Como se ha mencionado, la enfermedad integra una amplia gama de diagnósticos diferenciales con enfermedades como el paludismo, la hepatitis, la leptospirosis y otras enfermedades de la ictisis y/o hemorrágicas, que no se cierraen en un alto porcentaje de casos no considerados por los registros de los sistemas de vigilancia.

En vista de esto, el PVCFA recomienda el enfoque sindrómico en la vigilancia mediante el uso de un único cálculo y mantenimiento mediante pruebas de laboratorio, como medios para determinar la oportunidad y aumentar la eficacia, adherencia científica y caracterización del sistema nacional de vigilancia epidemiológica, con el objetivo de postular la vigilia metódica y constante del síndrome febril icílico y/o hemorrágico en las unidades de servicio centinela, con el objetivo de postular la medición metódica y constante del síndrome febril itico y/o hemorrágico en las unidades de servicio centinela, con el objetivo de postular la medición metódica y constante del síndrome febril itico y/o hemorrágico en las unidades de servicio centinela, con el objetivo de postular la medición metódica y constante del síndrome febril itico y/o hemorrágico en las unidades de servicio centinela, con el objetivo de postular la medición metódica y constante del síndrome febril itico y/o hemorrágico en las unidades de servicio centinela, con el objetivo de postular la medición metódica y constante del síndrome febril itico y/o hemorrágico en las unidades de servicio cen $^{\text {tine }} \mid \mathrm{a}$, 
La vigilancia entomológica también es una forma de combatir la enfermedad, especialmente a través de la convulsión de vectores silvestres en lugares donde se producen epizootias y/o casos humanos.

Además, el fortalecimiento de la capacidad de laboratorio es esencial, especialmente cuando se considera que el principio de este subcomponente es mejorar la eficacia de laboratorio para la identificación temprana del virus de la fiebre amarilla en primates que no los seres humanos y los propios seres humanos también ${ }^{2} 4$.

Con esto, se requiere la base para el diagnóstico con un enfoque en la investigación de virus en vectores potenciales, añadido a la construcción de datos para la detección de especies culicidas confinadas en áreas de investigación. Cabe destacar que, en la actualidad, la red de laboratorios procede de laboratorios centrales (LACN), con énfasis en el Instituto Adolfo Lutz, como se distingue regional y el Instituto Evandro Chagas como laboratorio de referencia nacional ${ }^{3} 0$.

La educación sanitaria es un punto a tener en cuenta, especialmente cuando se considera que se trata de un mecanismo importante y que debe ocupar una posición central en las acciones de vigilancia epidemiológica, ya que es necesario que la población entienda de hecho que la enfermedad sea para cambiar su conducta hacia la prevención ${ }^{9,10,20,21}$.

Por último, no puede dejar de mencionar las concepciones para la vigilancia de la fiebre amarilla en Brasil. En esta perspectiva, ha sido que una de las funciones de la vigilancia epidemiológica es vigilar el estado de salud de las poblaciones para ayudar a las políticas públicas con el fin de proporcionar lugares seguros y saludab ${ }^{\mathrm{le}} \mathrm{s} 15$, en vista de esto, busca realizar el seguimiento fiebre amarilla de un sesgo creativo, con el fin de llegar a todos los numerosos espacios de brotes de proliferación de la enfermedad, que, una vez detectados y mapeados, se convertirán en territorios de intervención ${ }^{1} 3$.

Por lo tanto, las acciones en este sentido deben orientarse a aclarar mejor los factores de riesgo ecológicos y ambientales que articulan la circulación del virus. 
Por lo tanto, la obtención de datos de la implementación de nuevas herramientas y nuevas perspectivas debe ofrecer la información más precisa para que se puedan postular directrices de acción viables, que se basen en bases de análisis firmes y precisas y interpretación, para que puedan generar nuevas recomendaciones de medidas de prevención y control que contribuyan realmente a la mejora de la vigilancia, prevención y control de la fiebre amarilla en el país ${ }^{20}$.

Iniciativas como estas apoyan la producción de conocimientos para la mejora de la gestión y puesta en funcionamiento del sistema de vigilancia epidemiológica. Por lo tanto, se debe aumentar la comprensión del proceso de diseminación del virus de la fiebre amarilla, teniendo en cuenta los factores que promueven el riesgo de exposición, los mecanismos de asimilación y la percepción temprana de la difusión viral de primates y vectores, y también que pueden clasificar y diferenciar la amenaza entre áreas predispuestas y vulnerables. Especialmente cuando los civiles no están vacunados ${ }^{1} 5$.

Sin embargo, todavía existen graves dificultades en los municipios para garantizar el pleno avance de un PVCFA notorio y eficaz, incluidos fondos de capital insuficientes, problemas de formación en laboratorio ante las demandas necesarias y las acciones de vigilia epidemiológico de los recursos debido a la mala gestión de los políticos locales. Además de los recursos financieros siempre escasos para el sector de la salud ${ }^{17}$.

Por lo tanto, se espera que los instrumentos ya en vigor puedan apoyar la expansión y formación del marco de los profesionales de la salud que están dispuestos a aceptar los desafíos de la puesta en marcha y la reestructuración de la vigilancia epidemiológica de la fiebre amarilla en el herramientas de apoyo para un mejor desempeño de su función como instrumento de cambio, intervención e incentivo sano sanitario. 


\section{CONCLUSIÓN}

Con la urbanización de los centros rurales, la posibilidad de aparición de ciertas enfermedades, como la fiebre amarilla, está aumentando, lo que tendría graves consecuencias para la salud pública, especialmente en las regiones donde la tasa de cobertura de vacunación es baja.

La modificación del medio ambiente causada por la actividad maderera, la apertura de caminos, la agricultura, entre otros, exponen accidentalmente a los individuos no inmunizados a vectores invertebrados salvajes, siendo una de las principales formas de transmisión de la laberíntica en la Amazonía brasileña. Este hecho se constituyó a lo largo de los años como una justificación relevante para los numerosos casos de mortalidad que ocurrieron en los estados de la Amazonía Legal. Hasta principios de 2017, en Brasil, se identificaron casos episódicos en estados ubicados fuera de esta área. Sin embargo, los primeros meses de 2017 revelaron la necesidad de intensificar la vigilancia, dado que la expansión del brote involucra a otros estados además de Minas Gerais, como Goiás, Sao Paulo y Mato Grosso, además de los Estados amazónicos. Esta necesidad se explica por el hecho de que un paciente virulento de una zona endémica de fiebre amarilla salvaje puede, asociado con las altas densidades de Aedes aegypti, constítuir un estímulo potencial para la reurbanización de la enfermedad en Brasil. Esta afirmación se ve reforzada por estudios actuales, que indican la presencia de Aedes aegypti en unos 21 estados brasileños $^{7}$, lo que refuerza la necesidad de vigilancia.

Desde esta perspectiva, surge la necesidad de un PVCFA eficiente, para que pueda, de hecho, ejercer control sobre los posibles focos de la enfermedad y, además, lograr a través de la educación en la disciplina de salud y la formación de los profesionales para mantener el riesgo de epidemia de la población urbana.

\section{REFERENCIAS}

1. VERONESI, R - Tratado de infectologia. São Paulo: Editora Atheneu, 1996. 
2. COSTA, GZA; ROMANO, APM; ELKHOURY, ANM; FLANNRY, B - Evolução histórica da vigilância epidemiológica e do controle da febre amarela no Brasil. In: Rev Pan-Amaz Saude. 2011. Disponível em: http://scielo.iec.pa.gov.br/scielo.php?pid=S217662232011000100002\&script=sci_arttext\&tlng=en. Acessado em: 01 dez. 2016.

3. MONATH, T.P - Yellow fever: an update. In: Lancet v.1, 2001, p.11-20.

4. QUARESMA, JAS - Apoptose e citocinas mediadoras da lesão hepática na febre amarela: subsídios para o redirecionamento dos mecanismos de lesão e suas consequências. 2003. 245-256f. Tese (Doutorado em Patologia Clínica) Faculdade de Medicina, Universidade de São Paulo, São Paulo, 2003.

5. LEÃO, RNQ - Doenças Infecciosas e parasitárias: enfoque amazônico. Belém: CEJUP, 1997.

6. GALLE, RP; HOFMANN, WJ; WALCZAK, H; SCHALLER, H; OTTO, GSW; KRAMMER, PH.; RUNKEL, L - Envolvement of the CD95 (APO-1/Fas) receptor and ligand in liver damage. In: J. Exp. Med. v.182, p.1223-1230, 1998.

7. MASSAD, E; COUTINHO, FAB; BURATTINI, MN; LOPES, LF - The risk of yellow fever in a dengue-infested area. In: Trans. R. Soc. Trop. Med. Hyg. v.95, 2001, p.570-574.

8. FRANCO, O - A história da febre amarela no Brasil. Rio de Janeiro: Ministério da Saúde; 2009.

9. LACERDA, A - Em busca de um tempo perdido: fontes visuais para a história da vacina contra a febre amarela. In: BENCHIMOL, J - Febre amarela: a doença e a vacina, uma história inacabada. Rio de Janeiro: FIOCRUZ; 2010.

10. PORTO, M - Marcos técnicos e legais para a descentralização do controle de endemias. Brasília: Ministério da Saúde, 2014.

11. BENCHIMOL, J - Febre amarela: a doença e a vacina, uma história inacabada. Rio de Janeiro: FIOCRUZ, 2010.

12. BRANCO, J - Vigilância da febre amarela no Brasil. Rio de Janeiro: Fundação Oswaldo Cruz, 2008.

13. CALHEIROS, L - A febre amarela no Brasil. Rio de Janeiro: Fundação Oswaldo Cruz, 2008. 
14. COSTA, GZA - Estudo das características epidemiológicas da febre amarela no Brasil, nas áreas fora da Amazônia Legal, período de 1999-2003 [dissertação]. Belém: Universidade Federal do Pará, 2005.

15. RIBAS, E - O mosquito como agente de propagação da febre amarela. Porto Alegre: Artmed, 2009.

16. SILVA, LM - Descentralização do controle de endemias. Brasília: Ministério da Saúde, 2011.

17. FARIA, GS - Endemias Rurais: métodos de trabalho adotados pelo DNERu. Rio de Janeiro: Ministério da Saúde, 2006.

18. HOMMA, A; CUNHA, J - Febre Amarela e Dengue. Rio de Janeiro: Fundação Oswaldo Cruz. 2007.

19. CAUSEY, C - Implantação dos estudos sobre arbovírus na região amazônica. 13 ed. Belém: Fundação Serviços de Saúde Pública, 2005.

20. BRASIL. Ministério da Saúde - Guia de vigilância epidemiológica. 15 ed. Brasília: Fundação Nacional de Saúde, 2012.

21. BRASIL. Ministério da Saúde - Plano de Intensificação das Ações de Prevenção e Controle da Febre Amarela no Brasil. Brasília: Ministério da Saúde, 2008.

22. DEMO, P - Metodologia do conhecimento científico. 5 ed. São Paulo: Atlas, 2009.

23. COSTA, GZA; ROMANO, APM; ELKHOURY, ANM; FLANNRY, B - Evolução histórica da vigilância epidemiológica e do controle da febre amarela no Brasil. In: Rev Pan-Amaz Saude. 2011. Disponível em: http://scielo.iec.pa.gov.br/scielo.php?pid=S2176-

62232011000100002\&script=sci_arttext\&tlng=en. Acessado em: 29 nov. 2016. 24. LIMA-CAMARA, T.N. Arboviroses emergentes e novos desafios para a saúde pública no Brasil. In: Rev. Saúde Pública. Disponível em: http://www.scielo.br/scielo.php?pid=S0034-

$89102016000100602 \&$ script=sci_arttext\&tIng=pt. Acessado em: 25 out. 2019.

25. LOPES, N; NOZAWA, C; LINHARES, R.E.C. Características gerais e epidemiologia dos arbovírus emergentes no Brasil. In: Revista Pan-Amazônica de Saúde.

Disponível em: 
http://scielo.iec.gov.br/scielo.php?script=sci_arttext\&pid=S217662232014000300007. Acessado em: 25 out. 2019.

26.CAMPOS, F.S. Replicação Viral. 2018. Disponível em: http://www.ufrgs.br/labvir/material/replicacao_med.pdfAcessado em: 25 out. 2019.

27. BRASIL. Centro de Vigilância Epidemiológica. Sobre a Febre Amarela. 2018. Disponível em: http://www.saude.sp.gov.br/resources/cve-centro-de-vigilanciaepidemiologica/areas-de-vigilancia/doencas-de-transmissao-por-vetores-ezoonoses/famarela.html. Acessado em: 25 out. 2019.

28. GOMES, A.C; et al. Ecologia de Haemagogus e Sabethes (Diptera: Culicidae) em áreas epizoóticas do vírus da febre amarela, Rio Grande do Sul, Brasil. In: Epidemiologia e Serviços de Saúde. 2010. Disponível em: http://scielo.iec.gov.br/scielo.php?script=sci_arttext\&pid=S167949742010000200003. Acessado em: 25 out. 2019.

29. SUCCI, R.C.M; FARHAT, C.K. Vacinação em situações especiais. In: Jornal de Pediatria. 2006. Disponível em: http://www.scielo.br/scielo.php?script=sci_arttext\&pid=S002175572006000400011. Acessado em: 25 out. 2019.

30.CAMPOS, A.C.T; MATTOS, S.V.M. Avaliação de requisitos referentes à implantação do sistema de gestão da qualidade nos Laboratórios Centrais de Saúde Pública. In: Revista do Instituto Adolfo Lutz. 2009. Disponível em: http://periodicos.ses.sp.bvs.br/scielo.php?script=sci_arttext\&pid=S007398552009000300019\&lng=pt\&nrm=iso. Acessado em: 25 out. 2019.

Enviado: Agosto, 2019.

Aprobado: Noviembre, 2019. 